Section Editor Mitchell S.V. Elkind, MD, MS

Charlene Ong, MD

Kevin Patel, MD

Erik Musiek, MD

Gregory Van Stavern, MD

Correspondence to

Dr. Ong:

ongc@neuro.wustl.edu
Supplemental data at Neurology.org

Mystery Case:

\title{
A young woman with isolated upbeating nystagmus
}

回舟

A 15 -week pregnant 21 -year-old woman initially presented with nausea, vomiting, and abdominal pain. The patient admitted to decreased oral intake over the past 4 weeks, including her prescribed prenatal vitamins. She was hypokalemic with elevated transaminases and gallstone pancreatitis was confirmed by imaging. Prior to cholecystectomy, fetal heart tones were lost and intrauterine fetal demise occurred. The patient underwent dilation and evacuation as well as cholecystectomy. She was discharged home but returned within 1 week with persistent nausea and vomiting. She had no neurologic complaints at the time. Basic metabolic panel on admission was unremarkable. On hospital day 2, she developed oscillopsia. Her examination was remarkable for large amplitude upbeating nystagmus (UBN) in primary position. She had gaze-evoked UBN in all other directions. The amplitude of the UBN increased on upgaze and dampened on downgaze. Smooth pursuit was impaired in all directions and saccades were dysmetric (video 1 on the Neurology ${ }^{\circledR}$ Web site at Neurology.org). Extraocular movements were intact with no evidence of ophthalmoplegia. Pupils were equal and reactive, and fundus examination was normal. Reflexes were present and symmetric, and gait was normal. The patient had no deficits on mental status examination. She was oriented to name, date, place, and situation and had no difficulty with complex commands, calculations, or short-term or longterm memory. Language was similarly intact. She demonstrated no ataxia or other focal abnormalities on examination.

\section{Questions for consideration:}

1. What is the differential diagnosis with this history and examination?

2. What is the next step in management for this patient? What tests would you order?

The initial differential diagnosis included a brainstem lesion due to an ischemic, inflammatory, or demyelinating process, thalamic or cerebellar arteriovenous malformation (AVM), and Wernicke encephalopathy (WE). The patient underwent MRI/magnetic resonance venography (MRV) of the brain with thin brainstem cuts, a lumbar puncture, and blood tests for inflammatory, paraneoplastic, and infectious etiologies. MRI revealed diffusion restriction and T2 hyperintensities of the bilateral medial thalami (figure). MRV revealed normal signal in the venous sinuses. CSF studies were normal, including 0 leukocytes and 0 oligoclonal bands.

\section{Questions for consideration:}

1. What is the differential of the imaging findings?

2. What other tests could you order?

Given the suspicion for WE, the patient was started on IV thiamine $500 \mathrm{mg}$ every 8 hours for 6 doses, then daily for 5 days with instructions to continue taking oral thiamine daily afterward. Her initial thiamine level was found to be low at $32 \mathrm{nmol} / \mathrm{L}$ (normal 70-130). Her nystagmus began to improve before discharge. At follow-up 2 weeks later, the patient reported improved oscillopsia but continued to experience some degree of UBN on up and leftward gaze. Three months after her hospitalization, her nystagmus was almost entirely resolved.

DISCUSSION We present a case of a 21-year-old woman in whom isolated UBN was the only presenting sign of WE. Early recognition of thiamine deficiency led to near-resolution of the patient's nystagmus and possibly prevented further gait and memory impairments. The classic triad of symptoms as originally described by Carl Wernicke in 1881 includes mental confusion, gait ataxia, and ocular motor dysfunction. However, all 3 symptoms are often not fully present, and this can lead to underdiagnosis. ${ }^{1-4}$ Wernicke's first patients exhibiting ocular abnormalities included 2 men with alcoholism and a young woman with persistent vomiting secondary to sulfuric acid ingestion. He describes her UBN and partial ophthalmoplegia as follows:

"Upward gaze provokes jerky movements of large amplitude; ultimately, however, the attempted excursion is completed. The same observations apply to downward gaze. Conjugate gaze to the left is significantly impaired. The left eye does not cross the midline despite considerable effort and quivering movements... Conjugate gaze to the right is restricted in a similar fashion." 


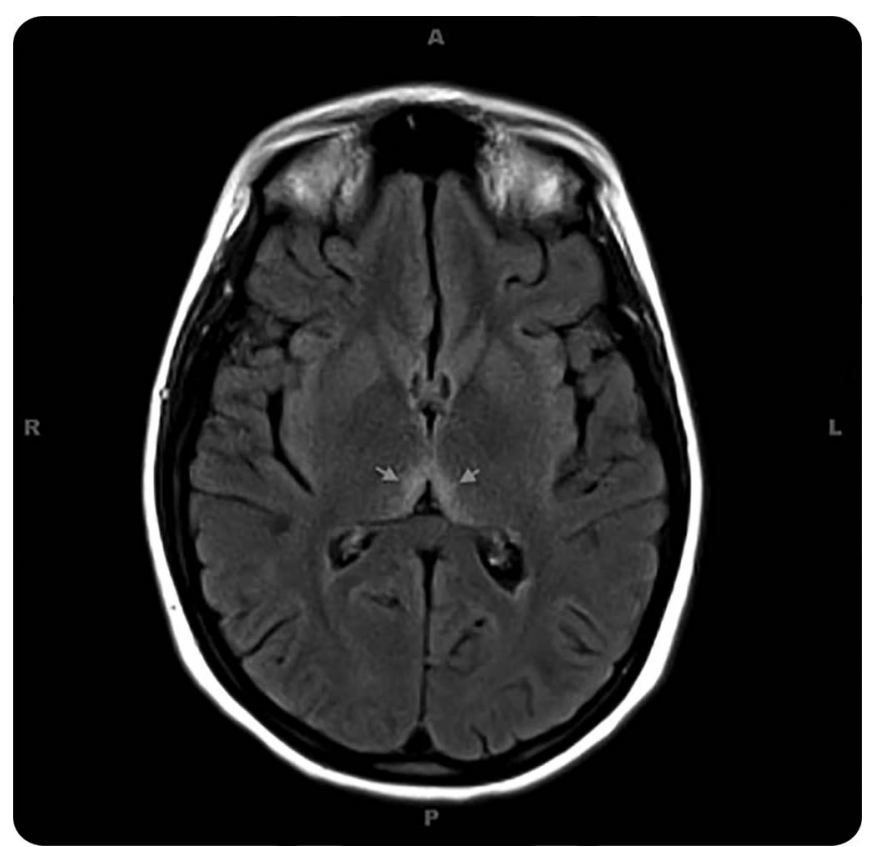

Clinically, neuro-ophthalmic signs associated with WE consist of both horizontal and vertical gazeevoked nystagmus (both upbeating and downbeating), weakness or paralysis of the lateral rectus muscles or conjugate gaze, and optic neuropathy. ${ }^{6}$

UBN such as in our patient is a form of central vestibular nystagmus. It should be differentiated from nystagmus evoked exclusively on upgaze (which is due to impaired gaze-holding) and the transient, mixed upbeat-torsional nystagmus in patients with benign positional paroxysmal vertigo. It has been reported in patients with lesions anywhere from the medulla to the midbrain. In addition to WE, UBN as seen in our patient can also be a manifestation of cerebellar degeneration, multiple sclerosis, infarctions of the medulla, and AVMs of the thalamus, midbrain, or cerebellum. ${ }^{7}$

Malnutrition for any reason in the context of ocular motility dysfunction, sustained nystagmus, confusion, or gait instability should prompt the practitioner to consider thiamine deficiency. Because the body stores only between 30 and $50 \mathrm{mg}$ of thiamine at a time, these reserves may be depleted in as little as 4 to 6 weeks. ${ }^{8}$ Conditions including hyperemesis gravidarum, cyclic vomiting, pancreatitis, and anorexia may result in a depletion of these stores. In our patient, protracted poor nutritional intake due to hyperemesis gravidarum compounded by gallstone pancreatitis is the likely culprit.

The urgency with which thiamine deficiency should be diagnosed and treated cannot be overstated.

With appropriate treatment, recovery of visual manifestations may begin within hours or sooner. ${ }^{6}$ Horizontal nystagmus may disappear within minutes; ptosis and lateral and vertical gaze palsies often recover completely within 1 to 2 weeks. Central vestibular nystagmus may persist for several months. ${ }^{6}$ Mild ataxia may remain in up to $60 \%$ of patients. However, once memory impairment occurs, only $20 \%$ of patients experience complete recovery. ${ }^{6}$

Untreated, WE results in death in up to $20 \%$ of cases, ${ }^{2}$ and leads to Korsakoff syndrome, an irreversible condition characterized by severe retrograde amnesia with prominent confabulation in $85 \%$ of survivors. ${ }^{9}$ For patients in whom the diagnosis remains unclear, imaging and laboratory tests may be useful, though treatment should not be delayed. Typical MRI findings include high signal intensity on T2 sequences in the bilateral medial thalami and periventricular regions of the third ventricle. ${ }^{10}$ Thiamine and transketolase are 2 laboratory tests that may indicate thiamine deficiency, though there are no definitive levels under which WE is expected to occur. ${ }^{7}$

Isolated UBN is an atypical but reported manifestation of thiamine deficiency. Prompt recognition is important to prevent the full and often irreversible constellation of symptoms associated with WE.

\section{AUTHOR CONTRIBUTIONS}

Dr. Ong wrote the manuscript and prepared it for submission. Dr. Patel edited the manuscript and video. Dr. Musiek provided commentary on the manuscript especially in relation to radiographic findings. Dr. Van Stavern provided commentary on the manuscript especially in relation to the ophthalmologic manifestations.

\section{STUDY FUNDING}

No targeted funding reported.

\section{DISCLOSURE}

The authors report no disclosures relevant to the manuscript. Go to Neurology.org for full disclosures.

\section{REFERENCES}

1. Victor M, Adams RD, Collins GH. The WernickeKorsakoff Syndrome and Related Neurological Disorders Due to Alcoholism and Malnutrition, 2nd ed. Philadelphia: FA Davis; 1989:61-110.

2. Harper CG, Giles M, Finlay-Jones R. Clinical signs in the Wernicke-Korsakoff complex: a retrospective analysis of 131 cases diagnosed at necropsy. J Neurol Neurosurg Psychiatry 1986;49:341-345.

3. Torvik A, Lindboe CF, Rogde S. Brain lesions in alcoholics: a neuropathological study with clinical correlations. J Neurol Sci 1982;56:233-248.

4. Antunez E, Estruch R, Cardenal C, et al. Usefulness of CT and MR imaging in the diagnosis of acute Wernicke's encephalopathy. AJR Am J Roentgenol 1998;171:1131.

5. Wernicke C. Acute hemorrhagic polioencephalitis superior. In: Rottenberg DA, Hochberg FH, eds. Neurological Classics in Modern Translation. New York: Hafner Press; 1977:63-75.

6. Ropper AH, Adams and Victor's Principles of Neurology, 9th ed. New York: McGraw-Hill Medical; 2009:1109-1112. 
7. Miller N, ed. Walsh and Hoyt's Clinical Neuro-Ophthalmology, 6th ed. Philadelphia: Lippincott Williams \& Wilkins; 2005:1143.

8. Thomson AD, Guerrini I, Marshall EJ. Nutrition issues in gastroenterology series \#75: Wernicke's encephalopathy: role of thiamine: nutrition issues in gastroenterology. Pract Gastroenterol 2009;33:21-30.

9. Day E, Bentham P, Callaghan R, et al. Thiamine for Wernicke-Korsakoff syndrome in people at risk from alcohol abuse. Cochrane Database Syst Rev 2004;1: CD004033.

10. Zuccoli G, Pipitone N. Neuroimaging findings in acute Wernicke's encephalopathy: review of the literature. AJR Am J Roentgenol 2009;192:501-508.

\section{MYSTERY CASE RESPONSES}

The Mystery Case series was initiated by the Neurology ${ }^{\circledR}$ Resident \& Fellow Section to develop the clinical reasoning skills of trainees. Residency programs, medical student preceptors, and individuals were invited to use this Mystery Case as an educational tool. Responses were solicited through a group e-mail sent to the American Academy of Neurology Consortium of Neurology Residents and Fellows and through social media.

Fifty-eight percent of respondents to this Mystery Case correctly noted that the patient has UBN, which is maximal on upgaze. The second most common suggestion regarding her eye movement abnormality was opsoclonus ( $11 \%$ of responses), but unlike the movements shown in the video, opsoclonus is purely saccadic with no slow phase, involves multidirectional movements, and occurs in irregular bursts rather than rhythmically.

With regard to the neuroimaging findings, 56\% of respondents identified the bilateral medial thalamic hyperintensities seen on T2 fluid-attenuated inversion recovery MRI, and in terms of underlying diagnosis, 86\% correctly suspected WE. Other proposed diagnoses included autoimmune conditions such as paraneoplastic encephalitis and neuromyelitis optica.

As the authors have highlighted, it is important to have a high index of suspicion for WE-and a low threshold for thiamine supplementation - in patients with isolated eye movement abnormalities and a history compatible with nutritional deficiency. This is particularly true since early treatment can prevent the development of irreversible neurologic sequelae.

Andrew Schepmyer, MD

University of British Columbia, Vancouver, Canada 


\section{Neurology}

\section{Mystery Case: A young woman with isolated upbeating nystagmus \\ Charlene Ong, Kevin Patel, Erik Musiek, et al. \\ Neurology 2015;84;e17-e19 \\ DOI 10.1212/WNL.0000000000001178}

This information is current as of January 26, 2015

\begin{tabular}{|c|c|}
\hline $\begin{array}{l}\text { Updated Information \& } \\
\text { Services }\end{array}$ & $\begin{array}{l}\text { including high resolution figures, can be found at: } \\
\text { http://n.neurology.org/content/84/4/e17.full }\end{array}$ \\
\hline Supplementary Material & $\begin{array}{l}\text { Supplementary material can be found at: } \\
\text { http://n.neurology.org/content/suppl/2015/01/24/WNL.0000000000001 } \\
\text { 178.DC1 }\end{array}$ \\
\hline References & $\begin{array}{l}\text { This article cites } 6 \text { articles, } 1 \text { of which you can access for free at: } \\
\text { http://n.neurology.org/content/84/4/e17.full\#ref-list-1 }\end{array}$ \\
\hline Subspecialty Collections & $\begin{array}{l}\text { This article, along with others on similar topics, appears in the } \\
\text { following collection(s): } \\
\text { All Neuro-ophthalmology } \\
\text { http://n.neurology.org/cgi/collection/all_neuroophthalmology } \\
\text { Nystagmus } \\
\text { http://n.neurology.org/cgi/collection/nystagmus } \\
\text { Oscillopsia } \\
\text { http://n.neurology.org/cgi/collection/oscillopsia }\end{array}$ \\
\hline Permissions \& Licensing & $\begin{array}{l}\text { Information about reproducing this article in parts (figures,tables) or in } \\
\text { its entirety can be found online at: } \\
\text { http://www.neurology.org/about/about_the_journal\#permissions }\end{array}$ \\
\hline Reprints & $\begin{array}{l}\text { Information about ordering reprints can be found online: } \\
\text { http://n.neurology.org/subscribers/advertise }\end{array}$ \\
\hline
\end{tabular}

Neurology ${ }^{\circledR}$ is the official journal of the American Academy of Neurology. Published continuously since 1951, it is now a weekly with 48 issues per year. Copyright @ 2015 American Academy of Neurology. All rights reserved. Print ISSN: 0028-3878. Online ISSN: 1526-632X.

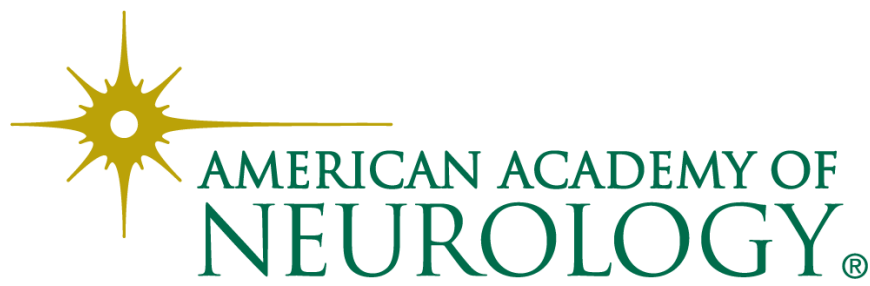

